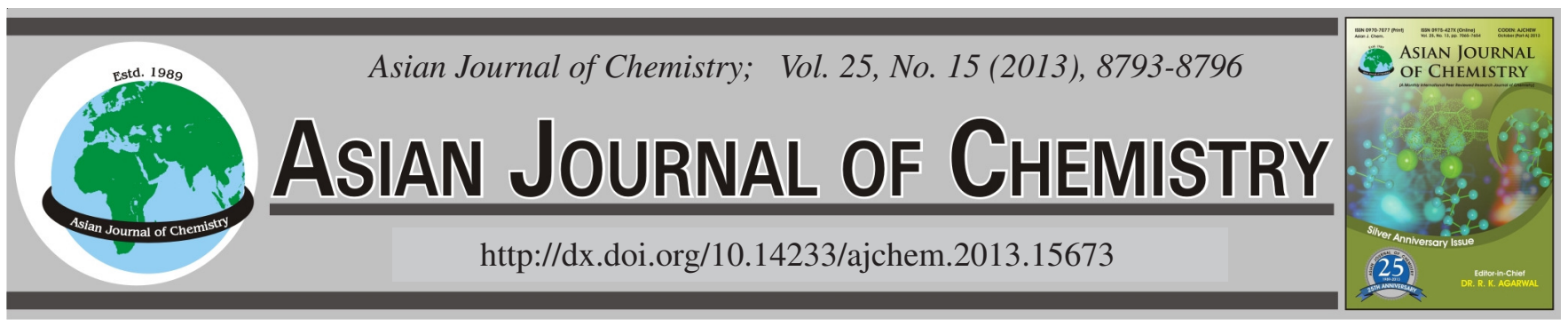

\title{
Feasibility of Anaerobic Co-Digestion of Waste Activated Sludge and Corn Straw to Produce Methane-Batch Experiment
}

\author{
Min Ji ${ }^{1}$, XIAOGANG JiANG ${ }^{2}$ and Fen WANG ${ }^{2, *}$
}

${ }^{1}$ State Key Laboratory of Hydraulic Engineering Simulation and Safety, Tianjin University, Tianjin 300072, P.R. China

${ }^{2}$ School of Environmental Science and Technology, Tianjin University, Weijin Road 78, Nankai District, Tianjin 300072, P.R. China

*Corresponding author: Tel/Fax: +86 27406057; E-mail: wangfen@tju.edu.cn

(Received: 23 April 2013;

Accepted: 29 August 2013)

AJC-14051

This work comprises, the feasibility of anaerobic co-digestion of waste activated sludge and corn straw to produce methane. It showed
that co-digestion of waste activated sludge and corn straw could increase $\mathrm{C} / \mathrm{N}$ of substrate and it was benefit for anaerobic digestion.
Anaerobic co-digestion efficiency was higher than anaerobic digestion efficiency of pure waste activated sludge. It was found that
co-digestion of waste activated sludge and corn straw could raise biogas yield and initial biogas production time was $3-6$ days before
initial time of pure waste activated sludge. Biogas production of co-digestion lasted for 27 days and cumulative yield was 7 times of
anaerobic digestion of pure waste activated sludge.

Key Words: Anaerobic digestion, Waste activated sludge, Corn straw, Water immersion.

ᄂ - - - - - - - - - - - - - - - - - - - - - - - - - - - - - - - - - - - - - - - - - - - - - - - - - - - - - - - - - - - - - - - - - - - - - - - -

\section{INTRODUCTION}

Anaerobic digestion $(\mathrm{AD})$ is an efficient biogas production process for municipal sludge treatment, which involves many advantages, such as sludge stabilization, sludge volume and mass reduction and methane production ${ }^{1,2}$. However, poor operational stability and low biogas yield prevent the technology from being widely applied ${ }^{3}$. Municipal sludge is mainly composed of waste activated sludge (WAS). Low carbon to nitrogen ratio $(\mathrm{C} / \mathrm{N})$ of waste activated sludge is a serious problem for anaerobic digestion. It is generally recognized that an optimum $\mathrm{C} / \mathrm{N}$ range is $20-30$ for anaerobic digestion ${ }^{4}$. The $\mathrm{C} / \mathrm{N}$ of waste activated sludge is only $4-10$, which is too low for anaerobic digestion. Low $\mathrm{C} / \mathrm{N}$ feedstock will result in low organic loading rate (OLR) and low biogas yield. Codigestion with other organic wastes with a high $\mathrm{C} / \mathrm{N}$ can increase $\mathrm{C} / \mathrm{N}$ and increase the amount of degradable carbon in feedstock, consequently, the biogas yield. Various researchers have reported that co-digestion of sludge with different organic wastes, such as fat, oil and grease ${ }^{5}$, food waste ${ }^{6}$, onion juice ${ }^{7}$ and other organic wastes ${ }^{8}$, can increase biogas yields.

China is a great agricultural country and crop straw output is large. It is reported that corn straw is the major crop straw and the output is about 220 million tons in 2008, accounting for $30.98 \%$ of the total straw and Northeast China is one of the main producing area ${ }^{9}$. Most of them are being burned in the field which results in air pollution and greenhouse gas emission. Anaerobic digestion is an environmental and friendly technology for corn straw, which can turn straw into energy ${ }^{10}$. Corn straw is a lignocellulosic biomass containing cellulose, hemicellulose, lignin and silicon ash. Its cellulose structure results in lower anaerobic digestion rate and biogas production and pretreatment is thought to be one of the effective methods to improve anaerobic digestion efficiency, which includes chemical $^{11}$, physical ${ }^{12}$ and biological methods ${ }^{13}$. In addition, $\mathrm{C} / \mathrm{N}$ of corn straw is high and nutrient balance will be achieved by co-digestion of waste activated sludge and corn straw.

In the work, $\mathrm{NaOH}$ solution and tap water were applied for corn straw pretreatment. Then batch experiment was carried out to evaluate the feasibility of co-digestion of waste activated sludge and pretreated corn straw. Biogas production, volatile fatty acids (VFAs) and other parameters were examined.

\section{EXPERIMENTAL}

Feedstocks and inoculum: The waste activated sludge in the experiments was collected from a wastewater treatment plant (WWTP, Tianjin, China), which handled 260,000 $\mathrm{m}^{3}$ wastewater $(60 \%$ domestic wastewater and $40 \%$ industrial wastewater) per day operating with anoxic/oxic activated sludge process. The sludge was precipitated gravitationally until total solids (TS) of the sludge reached $3 \%$. The ratio of volatile solid (VS) to total solids was $50 \%$ and $\mathrm{C} / \mathrm{N}$ was 4.9 .

The corn straw used in this study was obtained from the corn-field in Ji'nan, Shangdong Province, China. The straw 
was first grinded by a kibbler and then sieved by a 30 mesh sieve, stored at a cool and dry place before pretreatment. The main characteristics of corn straw were shown in Table-1.

\section{TABLE-1}

GENERAL CHARACTERISTICS OF RAW CORN STRAW

\begin{tabular}{lcccccc}
\hline C/N & TS & $\begin{array}{c}\text { VS/ } \\
\text { TS }\end{array}$ & $\begin{array}{c}\text { Water } \\
\text { content } \\
(\%)\end{array}$ & $\begin{array}{c}\text { Cellulose } \\
(\%)\end{array}$ & $\begin{array}{c}\text { Lignin } \\
(\%)\end{array}$ & $\begin{array}{c}\text { Hemicellulose } \\
(\%)\end{array}$ \\
\hline $53: 1$ & 88.9 & 90.3 & 11.1 & 40.4 & 25.5 & 24.4 \\
\hline
\end{tabular}

Based on the previous result ${ }^{14}$, the procedure was: $10 \mathrm{~g}$ raw corn straw was put in a $250 \mathrm{~mL}$ flask, then $150 \mathrm{~mL} 4 \%$ $\mathrm{NaOH}$ solution (called $\mathrm{NaOH}$ pretreatment) or $150 \mathrm{~mL}$ tap water (called water immersion pretreatment) was added into the flask and immersed the straw (solid-to-liquid ratio =1:15). After that, the flask was put in a heated thermostatic water bath at $30{ }^{\circ} \mathrm{C}$ for $48 \mathrm{~h}$. Then wet corn straw and supernatant was directly used for subsequent anaerobic digestion experiment (water immersion pretreatment), or after $\mathrm{pH}$ value of supernatant was close to neutral field (6.8-7.2) by adding concentrated hydrochloric acid, the wet corn straw and supernatant was used for anaerobic digestion experiment $(\mathrm{NaOH}$ pretreatment).

The inoculated sludge was collected from a one-stage large-scale mesophilic anaerobic digester of a WWTP located in Tianjin. The total solids was $55.2 \mathrm{~g} / \mathrm{L}$, and volatile solid was $24.9 \mathrm{~g} / \mathrm{L}$.

Batch experiment: The experimental setup was similar to that introduced by Weizhang ${ }^{10}$ (Fig. 1). The anaerobic digestion system was mainly composed of a $1 \mathrm{~L}$ Erlenmeyer flask as digester, a $1 \mathrm{~L}$ bottle as the biogas collector filled with sulfuric acid solution ( $\mathrm{pH} \mathrm{1)}$ ) and a $500 \mathrm{~mL}$ beaker as the receiver for sulfuric acid solution discharging from the collector. The whole system was put in the incubator with a constant temperature of $35 \pm 0.5^{\circ} \mathrm{C}$ (mesophilic condition). The volume of discharged sulfuric acid solution from the bottle represented biogas yield of the digester. It was measured once a day.

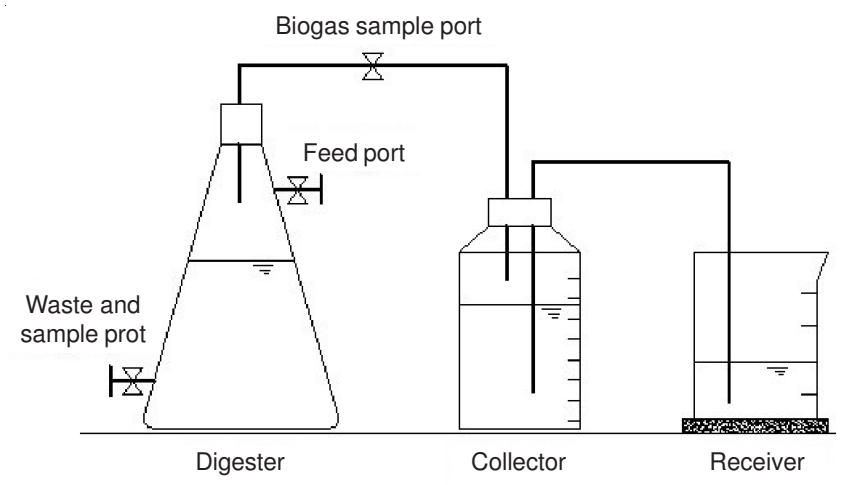

Fig. 1. Schematic diagram of anaerobic digestion system

In the research, 12 reactors were used for batch experiments (six in duplicate). Average values were used for discussions. Reactor 1 to reactor 4 were fed with a mixture of waste activated sludge and corn straw by $\mathrm{NaOH}$ pretreatment. The mass mixture ratios of waste activated sludge to corn straw were 2.3:1
$(\mathrm{M} 1: \mathrm{M} 2=2.3: 1, \mathrm{C} / \mathrm{N}=6.51$, reactor 1$), 1.8: 1(\mathrm{M} 1: \mathrm{M} 2=1.8: 1$, $\mathrm{C} / \mathrm{N}=7.09$, reactor 2), 1.2:1 (M1:M2 = 1.2:1, C/N = 8.38, reactor 3) and 0.6:1 (M1:M2 $=0.6: 1, \mathrm{C} / \mathrm{N}=11.84$, reactor 4$)$, respectively. Reactor 5 was fed with a mixture of waste activated sludge and corn straw by water immersion pretreatment and mass ratio of waste activated sludge to corn straw was 1.2:1 (M1:M2 = 1.2:1 C/N = 8.38, reactor 5) and reactor 6 was fed with pure waste activated sludge (pure waste activated sludge, $\mathrm{C} / \mathrm{N}=4.9$, reactor 6 ). The volume of feeding substrates was $80 \mathrm{~mL}$ and the same food/microorganism ratio $(\mathrm{F} /$ M) was kept at $0.006 \mathrm{gTS} / \mathrm{gTS}$ (R1-R6). The feeding inoculum (digested sewage sludge) quantity was $720 \mathrm{~mL}$.

Analytical methods: Total solids and volatile solid were determined according to standard methods ${ }^{15}$. Biogas yield was measured with sulfuric acid solution displacement. Biogas composition $\left(\mathrm{CH}_{4}\right.$ and $\left.\mathrm{CO}_{2}\right)$ was determined using a gas chromatograph (GC, SP-3430, Beijing Beifen-Ruili Analytical Instrument (Group) Co.Ltd.). Analytical conditions were as following: Thermal Conductivity Detector (TCD) $100{ }^{\circ} \mathrm{C}$; Chinese TDX-01 supporter (60-80 mesh); carrier gas: helium gas; carrier gas pressure $0.4 \mathrm{MPa}$; column temperature $50{ }^{\circ} \mathrm{C}$; injection chamber temperature $60^{\circ} \mathrm{C}$.

Volatile fatty acids e.g., acetic acid, propionic acid and n-butyric acid were measured using gas chromatograph (GC, SP-6890, Shandong Ruihong Chemical Apparatus Co.Ltd.). Parameters were: Flame ionization detector (FID) $220{ }^{\circ} \mathrm{C}$, capillary column, column temperature $120{ }^{\circ} \mathrm{C}$; carrier gas: nitrogen gas; carrier gas pressure $0.4 \mathrm{MPa} ; \mathrm{H}_{2}$ pressure 0.05 $\mathrm{MPa}$; air pressure $0 \mathrm{MPa}$; column head pressure $0.12 \mathrm{MPa}$; injection volume $1 \mu \mathrm{L}$.

The sodium concentration was measured using an atomic absorption spectrophotometer (AAS). The raw material composition was determined according to the literature ${ }^{16}$.

\section{RESULTS AND DISCUSSION}

Effect of pretreatment on corn straw components: It was found that main component contents of straw changed after pretreatment. As compared to contents of raw straw, the content of cellulose increased by $47 \%$ and the content of lignin decreased by $32 \%$ after $\mathrm{NaOH}$ pretreatment. It indicated that integration of cellulose and lignin was destroyed, which resulted in cellulose content increasing. It was found that $\mathrm{NaOH}$ pretreatment could increase cellulose degradation efficiency and it was supposed to be benefit for the subsequent anaerobic digestion. After $\mathrm{NaOH}$ pretreatment, hemicellulose content decreased by $55 \%$. The reason was that hemicellulose was alkali soluble, which could integrate with $\mathrm{OH}^{-}$as a result of hemicellulose loss.

As compared to the contents of raw straw, after water immersion pretreatment, the content of cellulose increased by $1 \%$ and the content of lignin decreased by $3.2 \%$ (Table-4). The cellulose growth rate was much lower than the one of $\mathrm{NaOH}$ pretreatment. It was different from $\mathrm{NaOH}$ pretreatment that hemicellulose content increased after water immersion. In general, the contents of corn straw changed little after water immersion pretreatment. As far as cellulose growth rate and lignin decrease rate, the water immersion pretreatment was less effective than the $\mathrm{NaOH}$ pretreatment. 


\section{Batch experiments}

Biogas production and methane content: The cumulative biogas production in reactor 1-reactor 6 (R1-R6) was shown in Fig. 2. The maximum cumulative biogas production was obtained in reactor $4(\mathrm{NaOH}$ pretreatment, $\mathrm{M} 1: \mathrm{M} 2=0.6: 1)$ and reactor 5 (water immersion pretreatment, $\mathrm{M} 1: \mathrm{M} 2=1.2: 1$ ), which biogas production was 4387 and $6557 \mathrm{~mL}$, at the end of 27 and 37 days, respectively. In contrast, cumulative biogas production in reactor 6 (pure waste activated sludge), which substrate was pure waste activated sludge, was only $711 \mathrm{~mL}$ at the end of 19 days. It demonstrated that co-digestion of waste activated sludge and corn straw could greatly improve biogas yield ( 7 times of pure waste activated sludge) and production time (18 days longer than pure waste activated sludge) and co-digestion could improve anaerobic digestion efficiency. In other reactors, cumulative biogas production and biogas production time were more than ones in Reactor 6 to varying degrees.

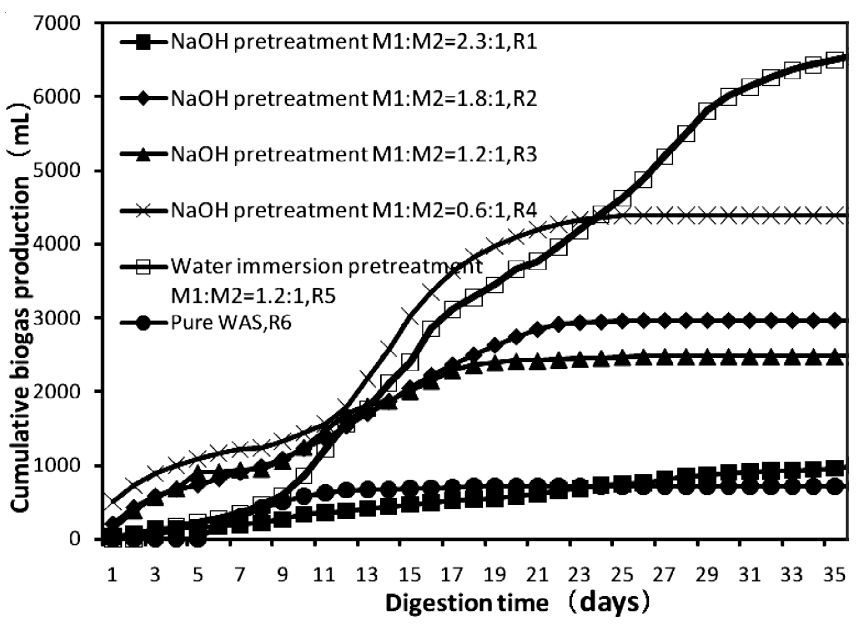

Fig. 2. Cumulative biogas production at different mixture ratios during batch experiment

The percentage variations of methane during batch experiment were shown in Fig. 3. In the beginning, except for reactor 6 (could not be examined for low production), methane percentage was 50-60\% for organic matters degradation in inoculated anaerobic sludge. After that, methane percentage decreased to $35-45 \%$ at the end of 7 days for hydrolysis and acidification of waste activated sludge and corn straw, during the time, volatile fatty acids concentrations was about $2000-3000 \mathrm{mg} / \mathrm{L}$, biogas production was inhibited. At the end of 12 days, methane percentage in reactor 1-5 increased to 50-60\% and maximum percentage was recorded as $60.6 \%$ in reactor 5 . In general, methane percentage in reactor 6 was more than one in other reactors, it might be due to higher protein content and lower carbohydrate content in waste activated sludge than ones in mixture of waste activated sludge and corn straw. It was reported that degradation of protein could obtain more methane production than one of carbohydrate ${ }^{17}$.

Volatile fatty acids concentration: Volatile fatty acids e.g., acetic acid, propionic acid, $n$-butyric acid were important hydrolysis and acidification products during anaerobic digestion. Volatile fatty acids concentrations variations in reactors during

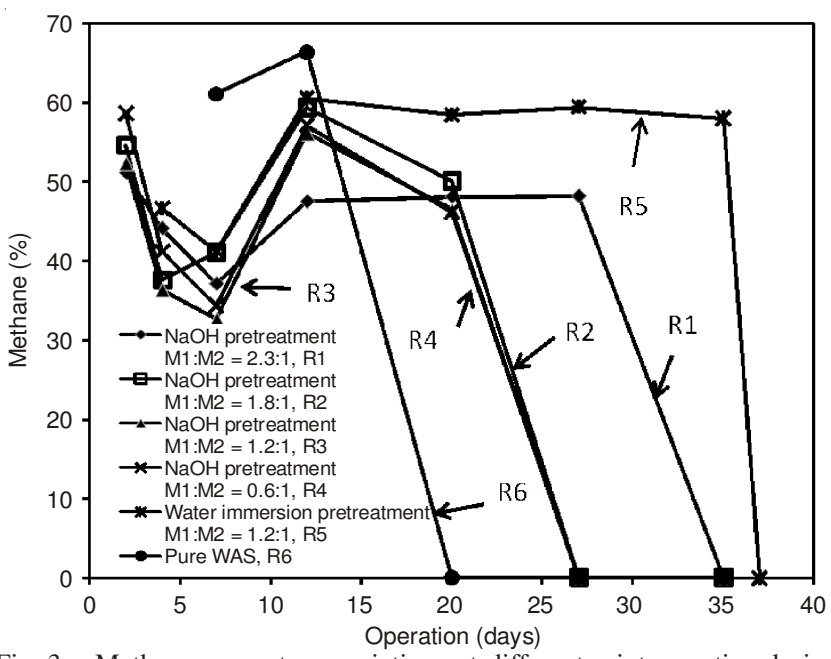

Fig. 3. Methane percentage variations at different mixture ratios during batch experiment

\begin{tabular}{lccc}
\multicolumn{4}{c}{ TABLE-2 } \\
\multicolumn{4}{c}{ CHANGES OF MAIN COMPONENTS OF } \\
CORN STRAW AFTER PRETREATMENT \\
\hline & Cellulose & Hemicellulose & Lignin \\
& $(\%)$ & $(\%)$ & $(\%)$ \\
\hline Raw corn straw & 40.4 & 25.5 & 24.4 \\
NaOH pretreatment & 59.4 & 11.4 & 16.5 \\
Water immersion pretreatment & 41.4 & 28 & 21.2 \\
\hline
\end{tabular}

batch experiment were shown in Fig. 4. From Fig. 4, it could be concluded that the main content of volatile fatty acids was acetic acid. For reactor $1-4$, the maximum volatile fatty acids concentrations were reached at the end of 12 days and acetic acid concentration was more than $4000 \mathrm{mg} / \mathrm{L}$. For Reactor 5, the maximum volatile fatty acids concentrations were recorded at the end of 7 days and acetic acid concentration was more than $4500 \mathrm{mg} / \mathrm{L}$ at the time. It indicated that hydrolysis and acidification rate in reactor 5 was faster than one in reactor 1-4. In contrast, volatile fatty acids concentrations in reactor 6 were much lower than ones in other reactors and this was why the biogas yield was much lower than one in other reactors.

It was worth noting that acetic acid concentrations after 12 days, were more than $2000 \mathrm{mg} / \mathrm{L}$ and $\mathrm{pH}$ values were lower than 6.5 , in reactor 1-4. It was supposed that sodium concentrations were high (840-2105 mg/L), it inhibited the methanogenic activity and then volatile fatty acids accumulated in reactors ${ }^{18}$. However, in reactor 5, there was little sodium, the acetic acid concentration decreased from 4516-450 mg/L in 5 days, which was utilized by methanogen as substrate for methane production and daily biogas production was increased from $80-400 \mathrm{~mL}$ at the same time.

\section{Conclusion}

Water immersion pretreatment is a promising method for corn straw pretreatment. Co-digestion of waste activated sludge and corn straw can increase $\mathrm{C} / \mathrm{N}$ of substrate and it is benefit for anaerobic digestion. Although $\mathrm{C} / \mathrm{N}$ is not in the optimum range (20-30), the anaerobic co-digestion efficiency is higher than anaerobic digestion of pure waste activated sludge. It is found that co-digestion of waste activated sludge and corn straw can raise biogas yield and cumulative biogas yield is 7 times of anaerobic digestion of pure waste activated sludge. 


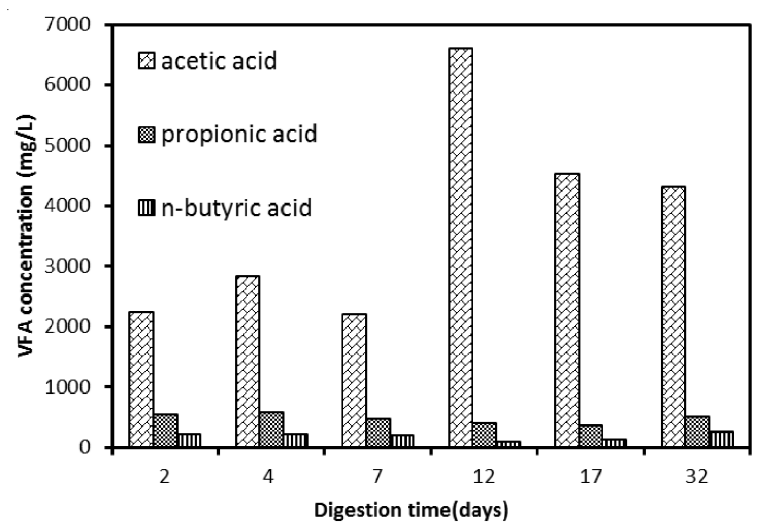

(a) Reactor $1, \mathrm{NaOH}$ pretreatment $\mathrm{M} 1: \mathrm{M} 2=2.3: 1$

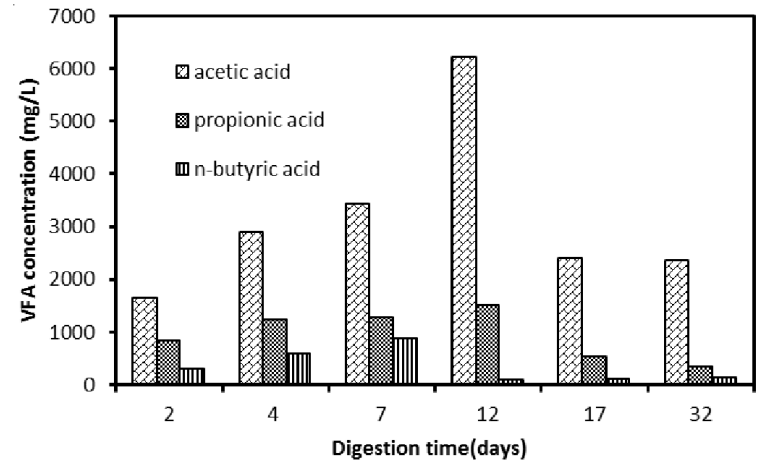

(c) Reactor 3, NaOH pretreatment M1:M2 = 1.2:1

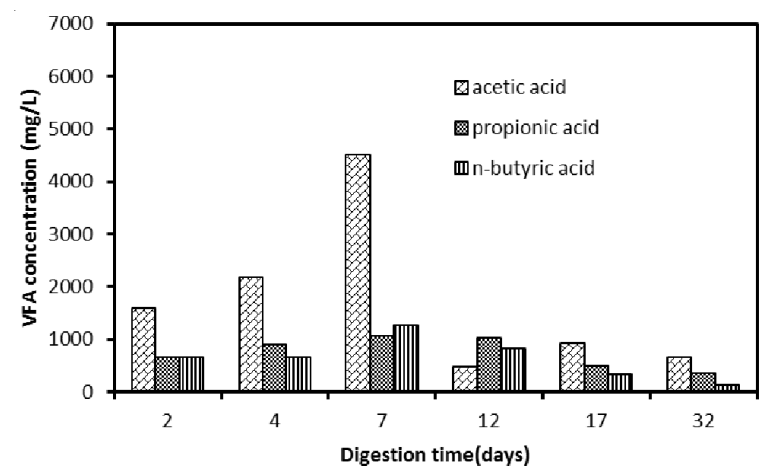

(e) Reactor 5, Water immersion M1:M2 = 1.2:1

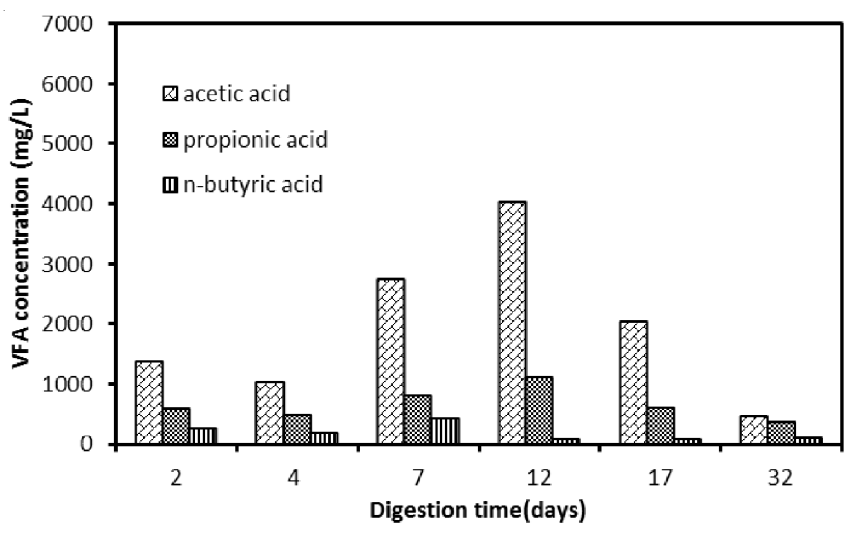

(b) Reactor 2, $\mathrm{NaOH}$ pretreatment $\mathrm{M} 1: \mathrm{M} 2=1.8: 1$

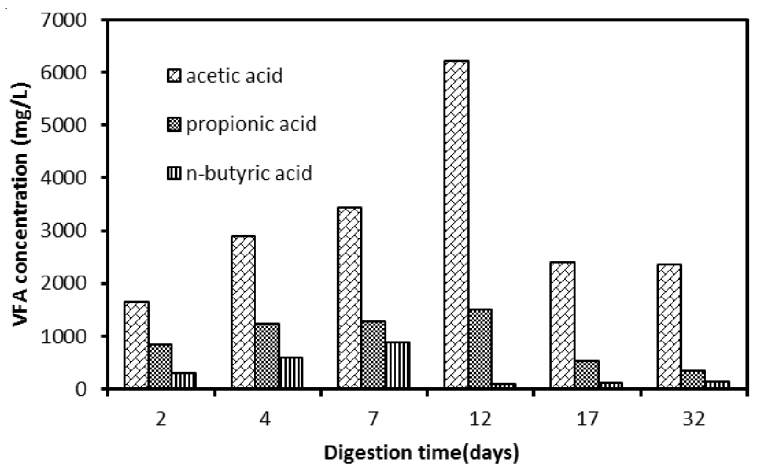

(d) Reactor 4, NaOH pretreatment M1:M2 = 0.6:1

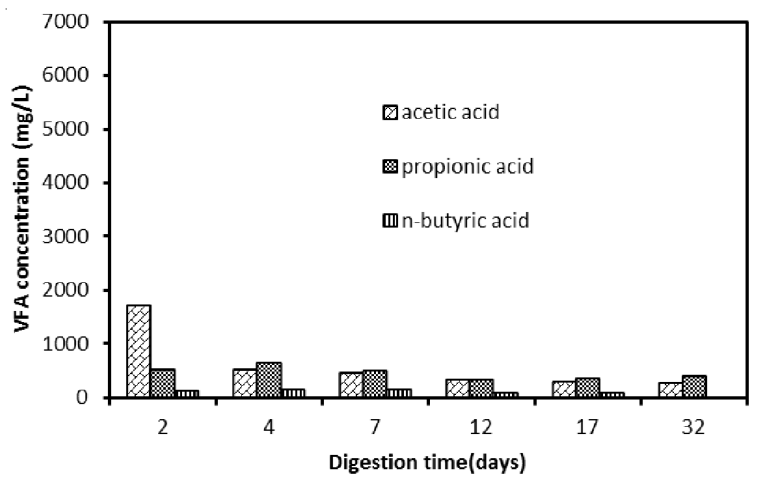

(f) Reactor 6, pure waste activated sludge

Fig. 4. Volatile fatty acids concentration variations during batch experiment in different reactors

\section{ACKNOWLEDGEMENTS}

This work was supported by National Natural Science Foundation of China (Grant No. 51008206), Young Faculty Foundation of Tianjin University and Special Fund for Agroscientific Research in the Public Interest.

\section{REFERENCES}

1. C. Bougrier, H. Carrère and J.P. Delgenès, Chem. Eng. J., 106, 163 (2005)

2. S. Luostarinen, S. Luste and M. Sillanpää, Bioresour. Technol., 100, 79 (2009).

3. M. Dupla, T. Conte, J.C. Bouvier, N. Bernet and J.P. Steyer, Water Sci. Technol., 49, 61 (2004).

4. G.F. Parkin and W.F. Owen, J. Environ. Eng., 112, 867 (1986).

5. W. Caixia, Z. Quancheng, F. Guiming and L. Yebo, Waste Manage., 31, 1752 (2011).

6. S. Chakkrit, P. Pensri, I. Tsuyoshi and R. Alissara, Int. J. Hydrogen Energ., 36, 14227 (2011).

7. T.R. Rowena and Z. Ruihong, Bioresour. Technol., 99, 631 (2008).

8. D.Z. Gregor, U. Nataša and R. Milenko, Biomass Bioenerg., 32, 162 (2008).
9. National Bureau of Statistics of China, China Statistical Year Book, Beijing, China: China Statistics Press (2011).

10. W.Z. Zhong, Z.Z. Zhang, W. Qiao, P.C. Fu and M. Liu, Renew. Energ., 36, 1875 (2011).

11. M.T. Garcia-Cubero, G. González-Benito, I. Indacoechea, M. Coca and S. Bolado, Bioresour. Technol., 100, 1608 (2009).

12. G. Yu, S. Yano, H. Inoue, S. Inoue, T. Endo and S. Sawayama, Biochem. Biotechnol., 160, 539 (2010).

13. A.A. Dias, G.S. Freitas, G.S.M. Marques, A. Sampaio, I.S. Fraga, M.A.M. Rodrigues, D.V. Evtuguin and R.M.F. Bezerra, Bioresour. Technol., 101, 6045 (2010).

14. F. Wang, Z.Y. Chen and M. Ji, Conditions optimization for $\mathrm{NaOH}$ pretreatment on corn straw using response surface methodology, International Conference on Electric Technology and Civil Engineering, Lushan, China, ICETCE 2011-Proceedings, pp. 3994-3996 (2011).

15. APHA, Standards Methods for the Examination of Water and Wastewater, American Public Health Assoc., Washington DC, USA, edn. 20 (1998).

16. L. Xuebin, X. Bo, Z. Yimin and A. Irini, Bioresour. Technol., 102, 7937 (2011).

17. L. Maya-Altamira, A. Baun, I. Angelidaki and J.E. Schmidt, Water Res., 42, 2195 (2008).

18. P.L. McCarty, Public Works, 95, 107 (1964) 